\title{
The Expertise Curse: How Policy Expertise Can Hinder Responsiveness ${ }^{*}$
}

\author{
Miguel M. Pereira \\ University of Southern California \\ m. pereira@usc.edu
}

\author{
Patrik Öhberg \\ University of Gothenburg \\ patrik.ohberg@som.gu.se
}

\begin{abstract}
We argue that policy expertise may constrain the ability of politicians to be responsive. Legislators with more knowledge and experience in a given policy area have more confidence in their own issue-specific positions. Enhanced confidence, in turn, may lead legislators to discount opinions they disagree with. Two experiments with Swedish politicians support our argument. First, we find that officials with more expertise in a given domain are more likely to dismiss appeals from voters who hold contrasting opinions, regardless of their specific position on the policy, and less likely to accept that opposing views may represent the majority opinion. Consistent with the proposed mechanism, in a second experiment we show that inducing perceptions of expertise increases self-confidence. The results suggest that representatives with more expertise in a given area are paradoxically less capable of voicing public preferences in that domain. The study provides a novel explanation for distortions in policy responsiveness.
\end{abstract}

\section{Word count: XXXX}

\footnotetext{
${ }^{*}$ We would like to thank Joan Barcelo, Daniel Butler, Adam Dynes, Peter Esaiasson, Luzia Helfer, Jonathan Homola, David Miller, Elin Naurin, Andrew Stone, Margit Tavits, Frédéric Varone, and Dalston Ward for their valuable feedback on the project. Early versions of this manuscript were presented at the American Political Science Association Annual Meeting in 2020, and the Comparative Politics Workshop at the University of Southern California. We received permission from the Ethics Commission at the University of Gothenburg to carry out the survey.
} 
Theories of political representation posit that reelection-seeking officials have incentives to be responsive to voters (e.g., Pitkin 1967, Dahl 1973). Consistent with this view, prior work shows that politicians update their positions based on public opinion polls (Butler and Nickerson 2011; Pereira 2020) and election results (Adams et al. 2005; Somer-Topcu 2009). However, there is ample variation in patterns of responsiveness. ${ }^{1}$ Lax and Phillips (2012) show that only half the policies adopted in American state legislatures are aligned with majority preferences. In Europe, there is growing evidence of inequalities in representation across different subconstituencies (Adams and Ezrow 2009; Giger et al. 2012; Homola 2019; O’Grady 2019).

Variations in responsiveness may partially result from different institutional incentives (Hobolt and Klemmensen 2008; Soroka and Wlezien 2010), contextual dynamics (Ezrow et al. 2019; Ezrow and Hellwig 2014; Giger and Klüver 2016), or representational roles adopted by different legislators (Dynes et al. 2018; Harden 2013). But responsiveness also varies according to the policy issue. For instance, Miller and Stokes (1963) demonstrated that US public opinion played a central role in shaping civil rights policies, but only a negligible role in foreign affairs. Why do reelection-seeking officials dismiss voters' opinions on certain policy issues?

This puzzle may partly be explained by the process through which politicians build their image of the electorate. In this article, we argue that policy expertise may constrain legislators' ability to be responsive. During their time in office - or from prior professional experience - elected officials often develop expertise in specific policy areas. Parliamentary committees encourage this form of specialization (Strøm 1998), and policy expertise is required for efficient policymaking. However, specialized knowledge can also influence how politicians respond to new information and make decisions.

Individuals with more expertise in a given area tend to have more confidence in their own beliefs in that domain (Dunning 2005; Fisher and Keil 2016; Tetlock 2005), and to be less open to different views (Ottati et al. 2015). Self-confidence and dogmatism may lead legislators with expertise in a specific domain to disregard opposing views on that issue. Yet policy responsive-

\footnotetext{
${ }^{1}$ Throughout the paper, we use the term responsiveness in a narrow sense to refer to mass-elite policy responsiveness (Harden 2013).
} 
ness requires accurate beliefs about the electorate (Broockman and Skovron 2018). Therefore, legislators may paradoxically be less capable of channeling constituent preferences in areas in which they are more knowledgeable. We refer to this argument as the the expertise curse.

We provide empirical support for the expertise curse in a pair of survey experiments involving Swedish elected officials. The experiments were included in two waves of the Panel of Politicians, a large biannual survey of legislators from all levels of government in Sweden. In the first experiment $(\mathrm{N}=1,669)$, we asked politicians to evaluate a hypothetical message from a group of voters asking them to support a specific policy. The voters' position on the issue was always at odds with the elicited preferences of the official to hold constant the propensity of legislators to discount opinions they disagree with (Butler and Dynes 2016). Additionally, we experimentally manipulated whether the initiative was within a policy area in which the legislator had high or low levels of expertise. The results confirm that politicians are more likely to disregard contrasting views in areas where they are more knowledgeable. Officials in the high-expertise condition were less likely to accept that the group of voters (1) understood the complexity of the issue, (2) based their opinion on facts, and (3) that their position represented the majority opinion. The findings are not explained by whether the group supports or opposes a given policy initiative, or by heterogeneity across issue areas. Subgroup analyses suggest that the main effects are more consistently driven by legislators with college degrees - a formal source of expertise - rather than passive expertise accumulated over time in office.

In the second study, we directly assess the causal mechanism implicit in the expertise curse. Consistent with our argument, we find that politicians who were induced to perceive themselves as experts were less likely to express doubts about their decisions in office.

Together, the findings have important implications for research on political representation and legislative politics. The expertise curse provides a novel explanation for distortions in policy responsiveness. If legislators with specialized knowledge play a central role in drafting new legislation (Makse 2020), the ability of citizens to control public policy is constrained whenever policy experts disagree with the majority. The study reveals a trade-off between expertise and the repre- 
sentational roles adopted by legislators. Although voters consistently prefer their representatives to follow constituents' preferences (Carman 2007; Converse and Pierce 1979; Dassonneville et al. 2020), the expertise required for efficient policymaking limits legislators' ability to be responsive. Finally, the expertise curse can create obstacles for policy implementation. Dismissing public preferences can lead to lower compliance or resistance if policy solutions fail to take into account social context or cultural norms (e.g., Wilkinson and Fairhead 2017).

\section{Expertise and disagreement discounting}

Efficient policymaking requires policy expertise. In some contexts, legislators can partially outsource this skill (e.g., Hertel-Fernandez 2019). However, only elected officials can introduce bills and shape the legislative process directly. Recent studies have revealed specific ways in which legislators' individual expertise can shape the policymaking process. Policy innovations tend to be introduced by representatives with more specialized knowledge (Makse 2020; Miler 2017). Seminal theories of legislative organization also recognize the value of expertise in policymaking. According to Krehbiel (1991), the U.S. Congress committee system is meant to provide the chamber with the necessary information and expertise for legislating. Similar institutions designed to promote a division of labor in the legislative branch are common in Europe (e.g., Mattson and Strøm 1995; Strøm 1998). Committees promote specialization within relevant policy jurisdictions and provide valuable information to parliaments (Shepsle and Weingast 1994). Committee members act as 'low-cost' specialists who make the legislative activity more efficient (Gilligan and Krehbiel 1989). Hence, the institutional framework of most contemporary parliaments encourages legislators to develop specific policy expertise (Mattson and Strøm 1995).

However, expertise can simultaneously shape how legislators evaluate information and make decisions. Expertise produces self-assurance (Fisher and Keil 2016; Tetlock 2005). Individuals with more knowledge and experience in a given domain tend to have more confidence in their own beliefs within that field. However, this confidence is often unwarranted (Dunning 2005). 
Individuals who are induced to believe they are experts tend to overestimate the accuracy of their beliefs (Arkes et al., 1987; Trafimow and Sniezek 1994). Specialized knowledge can produce illusions of understanding in part because experts are less willing to admit when they do not know something in their area of specialization (Bradley 1981). Individuals tend to be more accurate at assessing their own knowledge in an unfamiliar domain than in a familiar field such as their college major (Fisher and Keil 2016). At the same time, recent scholarship suggests that expertise stimulates close-minded cognition, or dogmatism (Ottati et al. 2015). Accordingly, social norms entitle experts to adopt more dogmatic and forceful positions while encouraging laymen to be more open minded and accepting of criticism.

If legislators with specialized knowledge express similar forms of overconfidence and dogmatism, policy expertise can impair elected officials' ability to carry out other relevant tasks. An important role of representatives is to voice the preferences and interests of those who elected them (Pitkin 1967). ${ }^{2}$ However, in order to be responsive, politicians must account for the preferences of constituents with whom they agree and disagree. We argue that policy expertise constrains legislators' ability to incorporate the preferences of constituents they disagree with. The overconfidence induced by specialized knowledge can lead representatives to disregard opposing views in their areas of expertise. We argue that specialized knowledge, although a central feature in the policymaking process, can be an obstacle to policy responsiveness - what we call the expertise curse. We call it a 'curse' because it reflects an implicit bias that is activated without the official's awareness or control.

Our argument builds upon recent scholarship suggesting that legislators systematically dismiss the preferences of constituents they disagree with (Butler and Dynes 2016). Officials' tendency to discount contrasting views may result from motivated reasoning: when faced with facts or opinions that challenge pre-existing beliefs, individuals are more likely to dismiss or actively counterargue these arguments (Lodge and Taber 2013). The expertise curse hypothesis suggests

\footnotetext{
${ }^{2}$ Politicians can also be responsive by listening to citizens' wishes and explaining their own position to their constituency (Esaiasson et al. 2013; Harden 2013). In this project, we focus on the mechanisms that may facilitate or hinder policy responsiveness: legislators pursuing policies that are consistent with constituent preferences.
} 
that the propensity to dismiss contrasting views should be more acute in domains in which legislators have more expertise.

A possible interpretation of this argument is that expertise is 'bad' for political representation. We do not agree with this interpretation. Specialized knowledge is key to developing good policy solutions, and in several domains we should not expect the majority of voters to have an informed opinion. Managing a public health emergency like the COVID-19 pandemic is a good example of a context in which decision makers should listen first and foremost to experts. However, ignoring public preferences can be problematic. For instance, containment measures in response to a pandemic that are too strict or insensitive to specific cultural norms can backfire, leading to lower compliance and resistance (Wilkinson and Fairhead 2017).

\section{Testing the Expertise Curse}

To test the expertise curse hypothesis, we conducted two original survey experiments with Swedish elected officials. The experiments were embedded in separate waves of the Panel of Politicians, a biannual panel survey with national, regional, and local representatives, and administered by the Laboratory of Opinion Research at the University of Gothenburg. ${ }^{3}$

Our goal in the first study was to understand whether policy expertise constrains legislators' ability to incorporate contrasting views from constituents. Public officials evaluated a hypothetical policy appeal from a group of voters. Elements of the request - including the issue area were experimentally manipulated to isolate the effects of expertise. The position of the group of voters on the initiative was also manipulated to be always at odds with the officials' elicited preferences. We expected legislators to be more likely to disregard the opinion of voters in domains in which they have more expertise. We designed a second experiment to directly assess our proposed causal mechanism. In study 2 we test whether heightened perceptions of policy expertise increase officials' self-confidence and dogmatism.

In the remainder of this section, we describe the context in which the two studies were con-

\footnotetext{
${ }^{3}$ More information is available at https://lore.gu.se/.
} 
ducted and the extent to which the findings should apply to other contexts. We then describe the research design and report the results from each study.

\section{The Swedish context}

The Panel of Politicians is an online university-based panel that has been administered twice a year since 2011. The panel is composed of a diverse group of Swedish politicians from local, regional and national offices. All major parties are proportionally represented in the sample except for the anti-establishment party Sweden Democrats, which is somewhat underrepresented. Participants are recruited via invitations in large surveys like the Comparative Candidates Survey and the Kommun- och landstingsfullmäktigeundersökningen, and through direct appeals on the websites of elected assemblies at all levels of government. Our first experiment was fielded in wave 13 of the panel, administered between October 10 and November 13, 2019. A total of 1,861 elected officials participated in the survey (47\% response rate). The second experiment was integrated into wave 14 and fielded between June 1 and July 6, $2020(\mathrm{~N}=1,348)$. Table B1 (Appendix B) summarizes the demographic characteristics of both elite samples.

Sweden' parliamentary system features strong and cohesive parties elected via proportional representation. Politicians are first and foremost party representatives. Yet, preferential voting creates incentives for legislators to cultivate a more personalized relationship with voters. Candidates on a party list can improve their ranking if they receive more than $5 \%$ of the party votes in their constituency. Prior studies have found that although Swedish legislators are constrained by intra-party dynamics, they are committed to account for constituency preferences (Naurin and Öhberg 2018; Öhberg and Naurin 2016) and to act on voters' signals (Butler et al. 2017). Therefore, we expect the patterns uncovered here to generalize to most European countries that have both party-centric systems and some incentives for officials to establish a personal connection with voters.

Party-centric systems can raise concerns about the substantive consequences of the expertise curse. If each party collectively decides its policy positions, the individual biases of representa- 
tives with different areas of expertise may cancel out. However, at least in the Swedish context legislators are particularly influential within their areas of expertise. As described in Table 1, according to the 2010 wave of the Swedish Parliamentary Survey, 53\% of Swedish Members of Parliament (MPs) reported having a very good chance of influencing the position of their party group within their area of expertise, compared to only $9 \%$ outside their area of expertise. Hence, it is exactly in the areas in which legislators are more influential that their ability to incorporate constituent preferences might be constrained.

\section{Study 1: Expertise and disagreement discounting}

We designed the first study to assess whether policy expertise leads elected officials to discount positions that go against their own. The design builds upon previous efforts to study political elites' attitudes and behavior when interacting with voters (Butler and Dynes 2016; Harden 2013). As briefly introduced above, elected officials were asked to evaluate a policy appeal made by a group of constituents. We altered the content of the appeal to isolate the effect of expertise on politicians' responses to the message. Two pre-treatment items provided the information needed to build the vignette: 1) measures of policy expertise and 2) the officials' preferences on the policies included in the vignette. We describe each item in turn followed by the constituents' message and the outcome variables used to capture the response to the appeal.

Table 1: Perceptions of within-party influence by area of expertise among Swedish MPs

\begin{tabular}{lcc}
\hline & \multicolumn{2}{c}{$\%$ Ability to influence party position within } \\
\cline { 2 - 3 } & Own area of expertise & Outside area of expertise \\
\hline Very good & 53.2 & 8.8 \\
Fairly good & 43.2 & 62.9 \\
Fairly bad & 3.2 & 26.4 \\
Very bad & 0.3 & 2.0 \\
\hline
\end{tabular}

Note: Each column represents the distribution of MPs' responses to the question: "How do you rate your ability to impact your party group's position on issues within/outside your own expertise?” Source: 2010 Swedish parliamentary survey. 


\section{Measuring policy expertise and policy preferences}

Policy expertise results from years of accumulated knowledge and experience. The entire process through which individuals develop expertise cannot be credibly manipulated in a survey. Instead, we leveraged the natural variation in expertise between respondents across five salient issue areas: healthcare, education, immigration, social welfare, and housing. To measure policy expertise, we introduced the following item early in the survey:

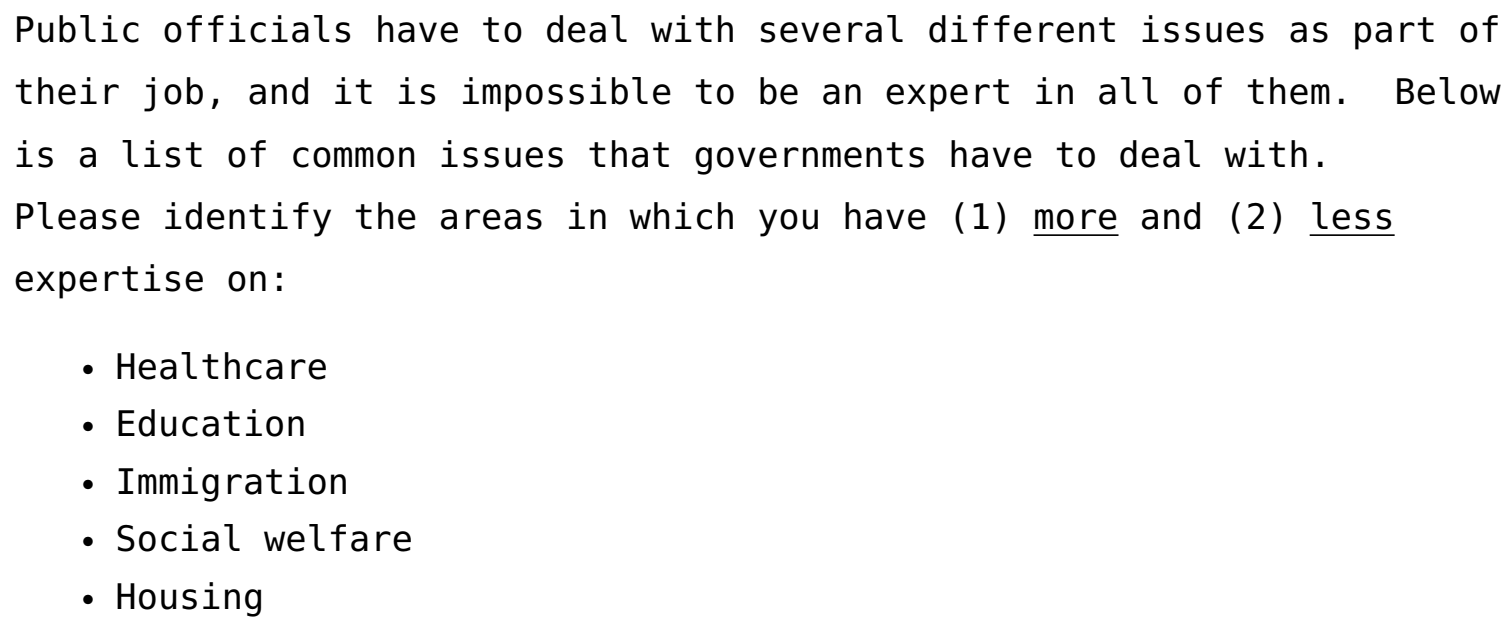

Officials were asked to identify the issue areas in which they were most and least knowledgeable, among the five domains listed. The distribution of higher- and lower-expertise issue areas is fairly uniform across respondents. While the modal area of expertise was education (30.5\% of respondents), the remaining four issue areas were selected by $11-24 \%$ of public officials in the study. The same is true for the areas in which legislators have lower levels of expertise (see Table B2 for the full distribution of responses).

We used this information to randomly assign respondents to a high- or low-expertise condition. Later in the survey, those in the high-expertise condition received a message from a group of constituents asking the legislator to endorse a specific initiative in his or her field of expertise. Officials in the low-expertise condition received a policy appeal in the area in which they were least knowledgeable of the five domains provided. ${ }^{4}$

\footnotetext{
${ }^{4} \mathrm{~A}$ potential concern with this empirical strategy is that it restricts the range of areas in which respondents can self-report high/low expertise. However, as discussed further below, the results are substantively the same among
} 
Table 2: Issue areas, corresponding policy initiatives, and share of supporters in the Panel of Politicians

\begin{tabular}{llc}
\hline Issue Area & Policy Initiative & \% Supporters \\
\hline Healthcare & Prevent private companies from operating hospitals & 41.8 \\
Education & Increase funding for charter schools & 37.5 \\
Immigration & Accept fewer refugees & 46.7 \\
Social Welfare & Introduce a ban on begging & 33.0 \\
Housing & Reduce interest rate deductions on house loans & 54.6 \\
\hline
\end{tabular}

For each area of expertise, we identified one specific policy initiative. Table 2 lists the initiatives associated with each policy jurisdiction. We identified policies that were salient at the time of the study, based on pre-tests with data from the Swedish Parliamentary Survey and the Swedish National Election Studies. ${ }^{5}$ For each issue, we ensured that elite and public support were sufficiently split, so that any position on the issue could be seen as credible. For example, the healthcare initiative concerned whether private companies should be prevented from operating hospitals. At the beginning of the survey, we collected officials' positions on each of these initiatives. To avoid contamination, additional policy questions were included in this section of the survey and the order of the items was randomized. Table 2 reports the share of legislators supporting each initiative. We used the officials' expressed preferences to ensure that the position of the group of constituents was always at odds with that of the public official. This way, we account for the tendency of legislators to disregard opinions they disagree with (Butler and Dynes 2016). Holding policy disagreement constant in the vignette allows us to isolate the effect of policy expertise.

\section{Policy appeal and legislators' response}

Finally, we asked respondents to evaluate a putative message sent from a group of constituents. ${ }^{6}$ Legislators in the high-expertise condition received an appeal on the issue area in which they had

subjects who identified the same area of expertise from a list of 14 issue areas in the following wave of the panel (see Figure D4).

${ }^{5}$ Data available at https : //val forskning . pol.gu. se/.

${ }^{6}$ Respondents were fully informed that this scenario was hypothetical. 
Box 1: Example of constituents' appeal on one of the five issue areas: healthcare

Different groups of voters contact politicians with political propositions.

Imagine the following: A group of voters is approaching you and wants you to [support/oppose] a proposal to ban companies from running hospitals. They believe that healthcare is facing major challenges. They see equality as a central issue. Their main argument is that a ban on companies for operating hospitals makes it [easier/more difficult] for vulnerable patients to choose the healthcare they need.

identified themselves as most knowledgeable, while those in the low-expertise condition received a policy appeal in their least knowledgeable issue area. Box 1 provides an example of the message presented to public officials - in this instance related to the healthcare policy. As described above, the constituents' position on the policy was the opposite of the elicited preferences of the legislator in order to keep policy disagreement constant. Appendix A presents the vignettes for the remaining four policy issues.

We measured legislators' reactions to the message by asking them to indicate their level of agreement with each of the following statements:

- The group likely understands the complexities of the issue

- The group likely based its opinion on facts

- The group likely holds this position strongly

- The group's opinion is the opinion of the majority of voters

The question wording comes from Butler and Dynes (2016). The first three statements capture the extent to which politicians recognized the validity of the arguments put forward by the constituents. The items provide specific rationales for politicians to discount the opinions conveyed in the message. While we could have directly asked legislators whether they would disregard the policy appeal, this approach would risk producing biased responses due to social desirabil- 
ity. The fourth statement captures respondents' ability to acknowledge that opposing views may be shared by the majority of voters. The responses were recorded on seven-point Likert scales ranging from "completely disagree" to "completely agree." We treat each item as a separate outcome variable. If the expertise curse hypothesis is correct, we should expect legislators to be more likely to disagree with each of the statements when the message pertains to a high-expertise issue area. According to our argument, the self-confidence and dogmatism generated by specialized knowledge should make elected officials more likely to overlook and discount contrasting views in their areas of expertise.

To measure the causal effects of expertise on legislators' responses to the policy appeal, we estimated linear regressions with covariate adjustment to improve precision (Gerber and Green 2012). The models control for respondents' age, educational level, and party. However, the same substantive results are obtained from bivariate regressions (see Figure D1 and Table C1 in Appendix D).

\section{Results}

Figure 1 presents the main results from study 1 . The $y$-axis lists the four statements used as outcome variables to assess the legislators' responses to the policy appeal. Each estimate represents the average difference in the level of agreement with the statements between officials in the highvs. low-expertise conditions. Therefore, the estimates capture the causal effects of policy expertise on legislators' responses to the policy request. Negative values indicate less agreement with each of the statements.

The results are consistent with the expertise curse hypothesis: policy expertise increases public officials' propensity to discount contrasting views from constituents. On the one hand, there is no evidence that policy expertise shapes beliefs about the strength of voters' opinions. This item, along with the first two statements described on the $y$-axis, provided different justifications for respondents to dismiss the policy appeal. On the other hand, respondents in the high-expertise condition were significantly less likely to believe that the group of constituents (1) understood 
Figure 1: The effects of expertise on legislators' ability to incorporate contrasting views

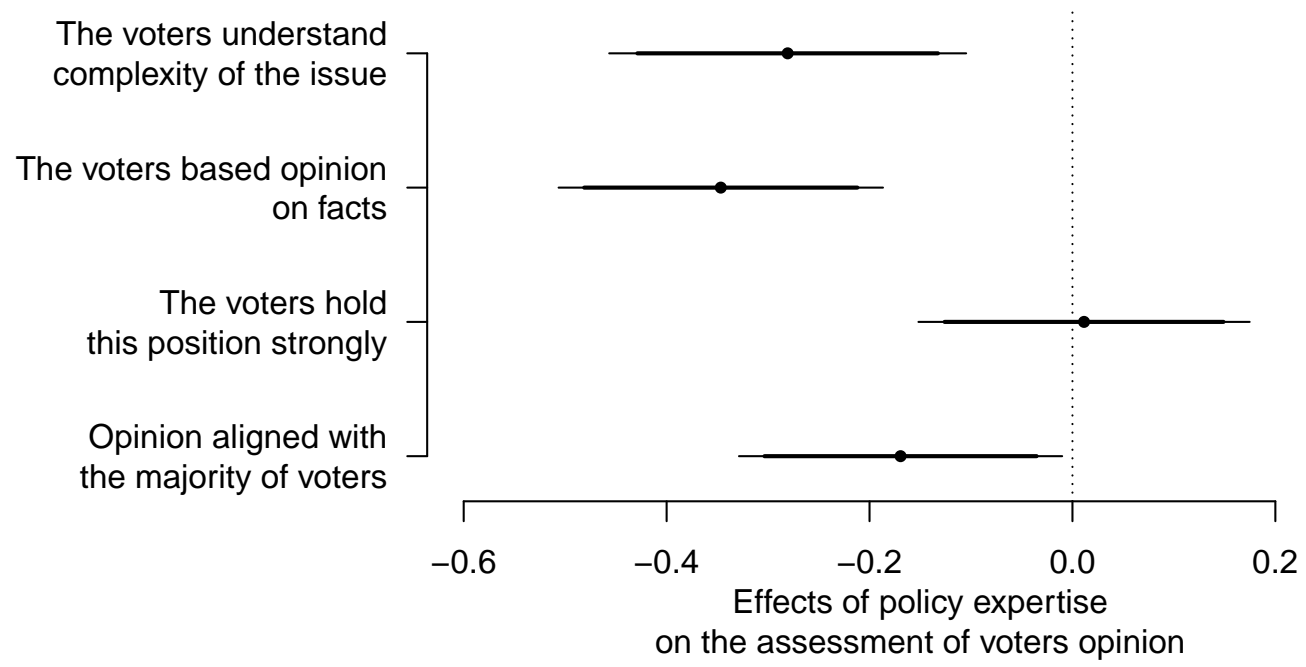

Note: Points are estimates of the causal effect of policy expertise on legislators' assessments of voters' opinion. Horizontal narrow/wide bars are 95\%/90\% confidence intervals. Agreement with each statement listed on the $y$ axis corresponds to a distinct outcome variable. Estimates and standard errors are derived from linear models with covariate adjustment for party, age, and education. Table C1 reports the full model results.

the complexity of the issue and (2) based their opinions on facts. Politicians are more likely to disregard opinions that go against their own in their areas of expertise. The statements included in the vignette provide concrete justification for this response. The effect sizes estimated are substantively meaningful. For instance, the top estimate in Figure 1 is -0.28 (standard error $=$ 0.09). Since the mean level of agreement with the statement "voters understand the complexity of the issue" is 2.8 (on a seven-point scale), the effect of policy expertise corresponds to a $10.0 \%$ decrease in agreement with the statement. In turn, the estimated effect of expertise on agreement with the idea that the group of voters based their opinion on facts (mean $=2.78$ ) is -0.35 , which corresponds to a $12.6 \%$ decrease relative to the mean value of the outcome.

Finally, officials in the high-expertise condition were less likely to accept that the position conveyed in the policy appeal reflected the view of the majority of voters $(-0.17$; s.e. $=0.08)$. Only $19.1 \%$ of respondents (across conditions) accepted that the policy appeal represented the majority opinion. Since, by design, the position of the group of voters was always at odds with the preferences of the legislator, this result is not surprising. Prior studies have found that politicians 
systematically underestimate the level of support for policies they oppose (Converse and Pierce 1986; Holmberg 1999). However, the patterns uncovered here suggest that elected officials are even more likely to discount contrasting views in their domains of expertise. ${ }^{7}$

Importantly, these patterns do not result from politicians in the high-expertise condition being more likely to receive a policy appeal that is counter to their own preferences (Butler and Dynes 2016). The vignettes were designed to hold policy disagreement constant. Also, since the position of the group of constituents varied based on the personal position of each individual legislator, the results should not be explained by the specific arguments advanced in favor of or against a given policy initiative.

Still, there might be meaningful differences across issue areas that could be driving the patterns we identify. To account for this possible source of heterogeneity, we replicated the main analyses with clustered standard errors and fixed effects by issue area. The main findings are robust to this more restrictive specification (see Figure D2, in Appendix D). The only exception is the coefficient for "opinion aligned with majority," which is no longer distinguishable from zero. These results further strengthen the interpretation of the main findings. Systematic differences across the five policy domains included in the study can only partially explain the tendency of policy experts to discount contrasting views in their areas of expertise.

The results could also be explained by differences in issue salience. Officials who have devoted more time to a given issue will likely care more about it. Hence, it is possible that legislators in the study were more likely to discount contrasting views in their areas of expertise not because of the self-confidence that comes with specialized knowledge, as hypothesized, but simply due to differences in issue salience. To account for this alternative mechanism, we replicated the main

\footnotetext{
${ }^{7}$ The position of the group of voters in the vignette was partly a function of the respondent's position on the issue. Hence, it is possible that differences in preferences between politicians could produce this result. Specifically, if the preferences of politicians in their domains of expertise are more closely aligned with the majority opinion (compared to politicians in the low-expertise condition), they should be less likely to accept that a contrasting appeal reflects the majority opinion. However, additional analyses show that this concern is not empirically grounded. Table D1 compares, for each policy domain, the share of supporters among officials in the high- and low-expertise conditions, as well as among a representative sample of voters. The preferences of officials in the high-expertise condition are not closer to the majority opinion. If anything, the opposite is true. In four out of five issue areas, the preferences of low-expertise officials were better aligned with the electorate as a whole.
} 
analysis accounting for how strongly respondents held their opinion on the policy issue in the vignette. As reported in Figure D3, the main effects of policy expertise remain unchanged after accounting for issue salience.

Finally, we assess how the list of issue areas included in the study may have affected the results. The experimental design required legislators to rank a limited set of policy areas in terms of expertise (see Table 2, above). These five domains are among the most relevant in local and regional governments from which the majority of officials in the sample were recruited (8890\%, as described in Table B1). Still, this design constraint may potentially bias the results. To address this concern, in wave 14 of the Panel of Politicians, fielded seven months after study 1, we provided respondents with a more extensive list of 14 issues. ${ }^{8}$ Two out of every three respondents recontacted $(67 \%)$ identified the same issue area in the original experiment and in the extended list of 14 issues. More importantly, we obtain the same substantive results when restricting the main analysis to this subset of respondents (full results in Figure D4). Hence, although this design constraint may have induced measurement error, it did not bias the results in a meaningful way.

Together, the findings suggest that policy expertise systematically constrains legislators' ability to voice public preferences. Elected officials with more specialized knowledge in a given domain are more likely to overlook opinions that are contrary to their own. Experts are also more likely to believe that views opposed to their own do not represent the majority opinion. In the next section we explore how different sources of specialized knowledge can moderate the expertise curse. The analysis provides a first test of our proposed causal mechanism.

\section{The role of formal and passive expertise}

Expertise in a given domain may come from legislators' experience in office, prior professional experience, or formal education. Understanding the forms of knowledge that are more likely to result in the expertise curse is important to shed light on its underlying mechanisms. In this

\footnotetext{
${ }^{8}$ The extended list of issue areas (presented in random order) was: business policies, culture, defense, education, environment, fiscal policy, foreign affairs, healthcare, housing, immigration, infrastructure, labor market, law and order, and social welfare.
} 
section we take a first step in this direction by exploring how two sources of expertise moderate legislators' tendency to discount contrasting views.

Formal expertise is a type of knowledge that results from extended study of a particular topic (e.g., Palmiero et al. 2020). Formal education often takes place early in life and over a relatively short period of time. The knowledge acquired through a college degree can quickly be forgotten, giving rise to illusions of understanding and overconfidence (Fisher and Keil 2016). To measure formal expertise, we created a binary measure that takes a value of 1 if a legislator completed a college degree, and 0 otherwise (50.1\% of officials in the survey had a college degree). Passive expertise, in turn, comes from "exposure through life experience and the position one occupies in a society or culture" (Fisher and Keil 2016; 1251). Officials with extended experience in office may feel more entitled to disregard contrasting views. Converse and Pierce (1986) found that French legislators with more years in office were more likely to misperceive constituency preferences. To capture passive expertise, we measured respondents' time in office. ${ }^{9}$

According to our theoretical argument, the expertise curse results from overconfidence and dogmatism. Both formal and passive expertise can produce overconfidence and less support for open-minded cognition. Hence, we expect the main effects we identified in the previous section to be driven mainly by officials with either a college degree or more experience in office. To test these predictions, we re-estimated the main model interacting the treatment variable with each source of expertise, respectively. ${ }^{10}$

Figure 2 presents the results. Panel (a) describes the effects of expertise on disagreement for politicians with and without a college degree. The patterns suggest that legislators with a college degree were more likely to downplay the opinions of constituents they disagreed with in their area of expertise. For the three outcomes that provided results consistent with the expertise curse in the main analysis, the coefficient for officials with a college degree is consistently larger (more negative). For instance, the effect of policy expertise on agreement with the statement that the

\footnotetext{
${ }^{9}$ The median respondent first entered office in 2002. To simplify the analysis, our measure of experience in office takes a value of 1 if respondents entered office before 2002, and 0 otherwise. The same substantive results are obtained with a continuous measure of experience, as described in Figure D5.

${ }^{10}$ Each model controls for the source of expertise that is not interacted with the treatment.
} 
Figure 2: The effects of expertise on legislators' ability to incorporate contrasting views, by form of expertise

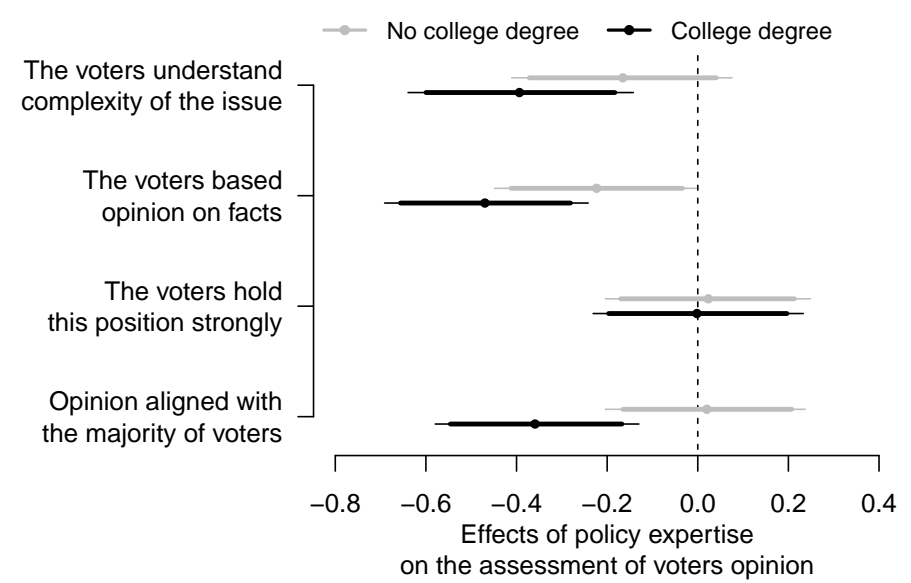

(a) Formal expertise: education

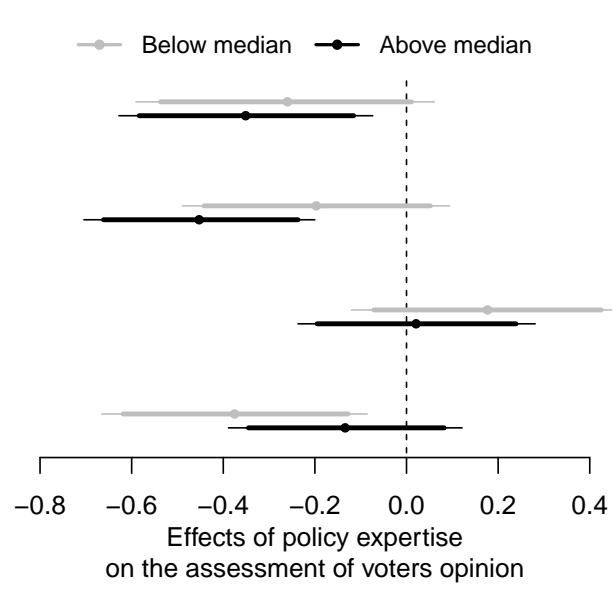

(b) Passive expertise: time in office

Note: Points are estimates of the causal effect of policy expertise on legislators' assessments of voters' opinion, among officials with/without a college degree (panel a) and officials with above-/below-median experience in office (panel b). Horizontal narrow/wide bars are $95 \% / 90 \%$ confidence intervals. Agreement with each statement listed on the $y$-axis corresponds to a distinct outcome variable. Estimates and standard errors derived from linear models with covariate adjustment for party and age. Full model results in Tables C2 and C3.

message reflects the majority opinion is virtually zero among officials without a college degree (estimate $=0.02$; std. error $=0.11$, but negative and substantively large for respondents with a college degree (estimate $=-0.36$; std. error $=0.12)$. Officials with a college degree were therefore significantly less likely to accept that opposing views in their area of expertise could represent the opinion of the majority ( $p$-value for difference in means $=0.02$ ).

Panel (b), in turn, describes how experience in office moderates the effects of expertise. The results provide less conclusive evidence. Representatives with above-median experience are slightly more likely to dismiss contrasting views, but the differences are small and indistinguishable from zero. The $p$-values for difference in means in the first two outcomes are 0.51 and 0.42 , respectively. The effects of expertise on the belief that contrasting views reflect the majority position (the two bottom estimates) are in the opposite direction. The estimate is distinguishable from zero only among politicians with less experience in office.

Together, the results suggest that the tendency of elected officials to discount contrasting 
opinions is more consistently driven by respondents with formal expertise. This result is in line with recent scholarship in cognitive psychology. Individuals with expertise that arises from extended study of a particular topic are less like to exhibit overconfidence outside their fields of knowledge, but more likely to overestimate their ability to explain their own areas of expertise (Fisher and Keil 2016). This overconfidence may result from "a failure to realize how much has been forgotten since they had maximum mastery of the topic" (1260). Importantly, neither formal education nor experience in office is exogenous. Since treatment heterogeneity is not causally identified, the results should be interpreted as suggestive.

\section{Study 2: Mechanism test}

In study 1 we uncovered a relationship between expertise and the way politicians respond to policy appeals from constituents. Officials with more knowledge of and experience in a given domain are more likely to discount opinions they disagree with. We argue that this relationship may be explained by a combination of overconfidence and dogmatism. Policy expertise can induce illusions of understanding, leading experts to overestimate the accuracy of their beliefs (Bradley 1981) and to engage in less open-minded cognition (Ottati et al. 2015). Consistent with this view, in the previous section we show that politicians with formal expertise are more likely to discount opposing opinions. However, we designed a second experiment to directly test the proposed mechanism.

The main goal of this study was to assess whether perceptions of policy expertise generate self-confidence and support for dogmatic attitudes. In order to induce perceptions of expertise, we randomly assigned officials to one of two groups. The first group was presented with the following expertise prime: 


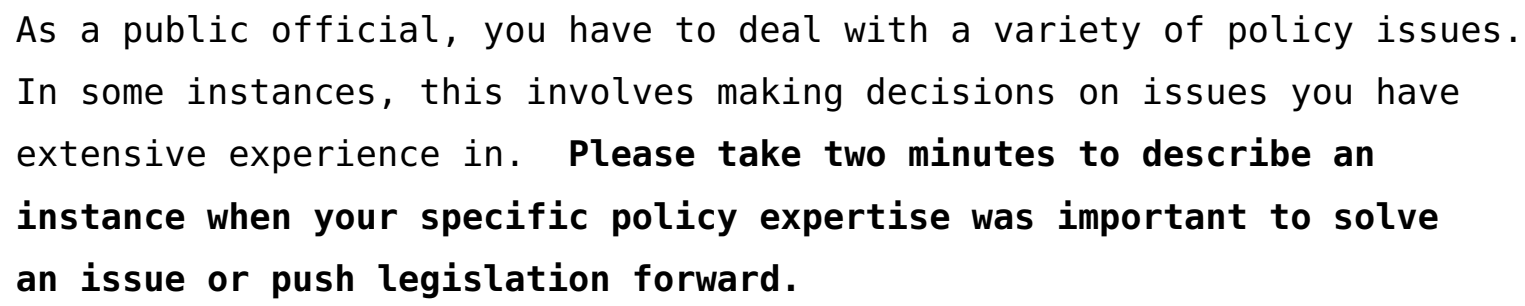

Respondents in this condition were asked to reflect on a specific episode while in office when their own expertise was important to solve an issue. This design builds upon prior experimental work using the controlled recollection of past events to induce specific beliefs and emotions (e.g., Hadzic and Tavits 2019; Lerner et al. 2003). The goal of this intervention is to heighten respondents' self-perceptions of expertise. A second group received a placebo prime asking respondents to describe, in two minutes, how they first got interested in politics. ${ }^{11}$ We included a placebo to account for the possibility that the recollection task, per se, could influence our outcomes of interest while not affecting respondents' perceptions of expertise.

After the recollection task, we asked both groups about the extent to which they agreed with the following statements: (1) "I often have doubts about my own decisions in office" and (2) "It is a waste of time to pay attention to certain ideas." Respondents could record their responses on a seven-point scale from "Completely disagree" to "Completely agree." The first item measures officials' degree of self-confidence. The second item captures their openness to different opinions (Ottati et al. 2015). We expected public officials who received the expertise prime to be less likely to agree with the first statement and more likely to agree with the second.

We included this second experiment in wave 14 of the Panel of Politicians. See Table B1 (Appendix B) for sample descriptives. A total of 1,143 elected officials participated in this section of the survey. Like in the first experiment, we rely on linear regressions with covariate adjustment to measure the causal effects of the expertise prime.

Figure 3 presents the main findings of the experiment. The estimates describe the causal

\footnotetext{
${ }^{11}$ The vignette presented to the placebo group was: "There are many paths to becoming a public official. Please take two minutes to describe how you first became interested in politics."
} 
Figure 3: The effects of priming expertise on self-confidence and dogmatism

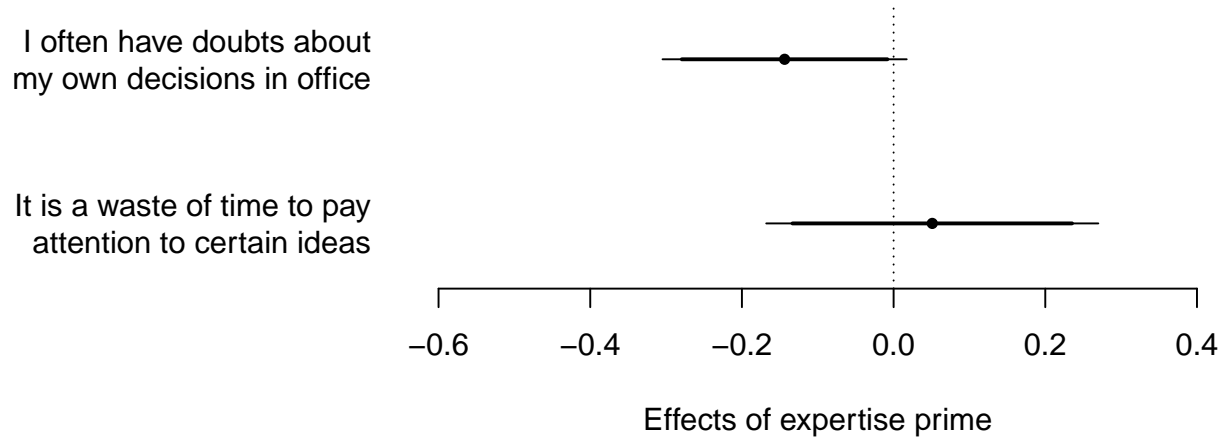

Note: Points are estimates of the causal effect of expertise on self-confidence (top estimate) and close-minded cognition (bottom estimate). Horizontal narrow/wide bars are 95\%/90\% confidence intervals. Estimates and standard errors derived from linear models with covariate adjustment for party, age, and education. Full model results in Table C4.

effects of the expertise prime (relative to the placebo prime) on agreement with each of the statements described along the $y$-axis. The top estimate reveals that heightened perceptions of expertise are associated with more self-confidence. Public officials who received the expertise prime were less likely to express doubts about their decisions in office $(-0.14 ; p$-value $=0.08)$. This result is consistent with our argument that expertise is associated with more self-confidence. In turn, the effect of expertise on our measure of dogmatism (bottom estimate in Figure 3) is positive, but small and indistinguishable from zero $(0.05$; s.e. $=0.11)$. Representatives who received the expertise prime were not significantly more likely to agree with the statement that paying attention to certain ideas is a waste of time. This null effect may be explained, in part, by a relatively weak treatment or as a result of social desirability bias.

Still, given the inherent challenges of effectively manipulating perceptions of expertise, we interpret these findings as reassuring. The results are consistent with the mechanism we proposed to explain the expertise curse. On average, politicians who received the expertise prime were less likely to express doubts about their own decisions, and were (suggestively) less open minded. 


\section{Discussion}

Good policy outcomes require legislators to have expertise in different issue areas. Committee systems in most legislative branches encourage this form of specialization. At the same time, elections create incentives for responsiveness. In this article we argue that there might be a tradeoff between electing policy experts and representatives who pursue policies that are consistent with voter preferences. We refer to this phenomenon as the expertise curse.

Consistent with our argument, we show that policy expertise leads Swedish legislators to disregard the views of constituents with whom they disagree, regardless of the actual position expressed by voters. Experts are also less likely to believe that voters with preferences different to their own can reflect the position of the majority. Hence, the expertise curse systematically constrains legislators' ability to take public preferences into account when devising policies in their areas of expertise. In a second study, we show that self-confidence induced by specialized knowledge can partially explain these patterns.

The patterns uncovered do not appear to be unique to a specific issue. We find support for the expertise curse across five salient policy jurisdictions: healthcare, education, immigration, housing, and social welfare. Yet, our findings also have important limitations. First, to make sure the experimental design was focused and well powered to test the expertise curse, we held policy disagreement constant. Public officials were always presented with an appeal to support a policy they were opposed to. It is conceivable that the effects of expertise are less pronounced when politicians are asked to endorse policies they support. More research is needed to elucidate this question. That said, the expertise curse is no less relevant if it is limited to instances in which officials are confronted with opposing views. Dealing with disagreement is an intrinsic element of the policymaking process. Decision makers' ability to recognize the value of contrasting views is key to finding compromise solutions, which are often required to move policy forward (Gutmann and Thompson 2014).

Second, we speculate that the expertise curse results from a heightened sense of self-confidence and close-minded cognition - processes that are associated with more specialized knowledge in a 
given domain. The link between expertise and overconfidence is well established in the cognitive literature (Dunning 2005; Fisher and Klein 2016; Ottati et al. 2015; Tetlock 2005). Consistent with this research, in study 2 we provide evidence that heightened perceptions of expertise induce self-confidence. Still, the mechanisms proposed are not exhaustive. For instance, it is possible that officials are more likely to discount public appeals in their areas of expertise because interest groups disproportionately target policy experts when trying to raise attention to an issue. This process could create case overload and lead legislators to become more skeptical about who is responsible for the appeal, or the extent to which it is rooted in real concerns of the electorate. Future individual-level research with political elites could test this and other complementary mechanisms directly.

The study contributes to scholarship on policy responsiveness, legislative politics, and elite behavior. First, the expertise curse provides a novel explanation for distortions in mass-elite policy responsiveness. By restricting the ability of legislators to incorporate public signals, the expertise curse implies that the prospects for constituency control are weaker when politicians disagree with constituents in their areas of expertise. Whether this implication can be interpreted as normatively positive or negative, it depends on one's understanding of the appropriate role of representatives. However, we do believe the expertise curse can raise obstacles to policy implementation. If policy experts consistently disregard public opinion, constituents can be less willing to acquiesce. Policy solutions that are insensitive to social or cultural norms can lead to lower compliance or backlash (Wilkinson and Fairhead 2017).

The findings also shed light on the value of descriptive representation. In study 1 we show that politicians with college degrees are more likely to discount contrasting views in their areas of expertise. At the same time, recent scholarship shows that less privileged subconstituencies are less likely to convert their preferences into policy (Giger et al. 2012; O'Grady 2019). Without questioning the importance of electing representatives with formal expertise, our results suggest that inequalities in policy responsiveness can be mitigated by electing a more diverse group of legislators. 
The expertise curse can also contribute to debates over parliamentary reform. Parliaments around the world rely on the specialized knowledge of their members to find solutions for different policy issues. However, the results uncovered here suggest the existence of a trade-off between expertise and responsiveness. Reformers interested in curbing the systemic low levels of trust in the legislative branch (Hibbing and Theiss-Morse 1995; Leston-Bandeira 2012) may benefit from recognizing this trade-off and incorporating it in their efforts to strengthen the links between voters and their representatives in parliament.

Finally, the study joins recent behavioral scholarship on elite behavior (e.g., Butler and Dynes 2016; Sheffer et al. 2018). By focusing on the cognitive processes underlying the decisions of elected officials, these studies shed light on different questions left open in long-standing debates in the discipline. In the context of this particular study, a natural next step involves exploring how elected officials can overcome the tendency to dismiss public opinion in their own areas of expertise. 


\section{References}

Adams, James, Samuel Merrill, and Bernard Grofman. 2005. A Unified Theory of Party Competition. Cambridge, UK: Cambridge University Press.

Adams, James, and Lawrence Ezrow. 2009. "Who do European Parties Represent? How Western European Parties Represent the Policy Preferences of Opinion Leaders." Journal of Politics 71(1): 206-223.

Arkes, Hal R., Caryn Christensen, Cheryl Lai, and Catherine Blumer. 1987. "Two methods of reducing overconfidence." Organizational Behavior and Human Decision Processes 39(1): 133144.

Bradley, James V. 1981. "Overconfidence in ignorant experts.” Bulletin of the Psychonomic Society 17(2): 82-84.

Broockman, David E. and Christopher Skovron. 2018. "Bias in Perceptions of Public Opinion among Political Elites.” American Political Science Review 112(3): 542-563.

Butler, Daniel M. and David W. Nickerson. 2011. "Can Learning Constituency Opinion Affect How Legislators Vote? Results from a Field Experiment.” Quarterly fournal of Political Science 6: $55-83$.

Butler, Daniel M., and Adam M. Dynes. 2016. "How politicians discount the opinions of constituents with whom they disagree." American fournal of Political Science 60(4): 975-989.

Butler, Daniel M., Elin Naurin, Patrik Öhberg. 2017. "Party Representatives' Adaptation to Election Results: Dyadic Responsiveness Revisited.” Comparative Political Studies 50(14): 19731997.

Carman, Christopher Jan. 2007. “Assessing preferences for political representation in the US.” Fournal of Elections, Public Opinion and Parties 17(1): 1-19.

Converse, Philip E., and Roy Pierce. 1979. "Representative roles and legislative behavior in France." Legislative Studies Quarterly: 525-562.

Converse, Philip E., and Roy Pierce. 1986. Political Representation in France. Harvard University Press.

Dahl, Robert Alan. 1973. Polyarchy: Participation and opposition. New Haven, CT: Yale University Press.

Dassonneville, Ruth, André Blais, Semra Sevi, and Jean-François Daoust. 2020. "How Citizens Want Their Legislator to Vote." Legislative Studies Quarterly. Available online at: https: //doi.org/10.1111/lsq. 12275.

Dunning, David. 2005. Self-Insight: Roadblocks and Detours on the Path to Knowing Thyself. New York, NY: Psychology Press.

Dynes, Adam M., Hans J. G. Hassell, and Matthew R. Miles. 2018. "Political Ambition and Con- 
stituent Service: Does Ambition Influence How Local Officials Respond to Electoral and Non-Electoral Service Requests?" Unpublished. Available at: http://adamdynes.com/ documents/WP_2018_dynes - etal_ambition-and - responsiveness . pdf (accessed 30 September 2020).

Esaiasson, Peter, Mikael Gilljam, and Mikael Persson. 2013. "Communicative responsiveness and other central concepts in between-election democracy." In Peter Esaiasson and H. Marthe Narud (ed.) Between-Election Democracy: the Representative Relationship After Election Day Colchester: ECPR Press: 15-33.

Ezrow, Lawrence, Timothy Hellwig, and Michele Fenzl. 2020. "Responsiveness, If You Can Afford It: Policy Responsiveness in Good and Bad Economic Times." The fournal of Politics. Available online at: https://doi .org/10.1086/707524.

Ezrow, L. and Timothy Hellwig. 2014. "Responding to voters or responding to markets? Political parties and public opinion in an era of globalization.” International Studies Quarterly 58(4): 816-827.

Fisher, Matthew, and Frank C. Keil. 2016. "The curse of expertise: When more knowledge leads to miscalibrated explanatory insight." Cognitive Science 40(5): 1251-1269.

Gerber, Alan S., and Donald P. Green. 2012. Field Experiments: Design, Analysis, and Interpretation. New York, NY: WW Norton.

Giger, Nathalie, Jan Rosset, and Julian Bernauer. 2012. "The poor political representation of the poor in a comparative perspective." Representation 48(1): 47-61.

Giger, Nathalie and Heike Klüver. 2016. "Voting against your constituents: How lobbying biases representation" American fournal of Political Science 60(1): 190-205.

Gilligan, Thomas W., and Keith Krehbiel. 1989. "Asymmetric information and legislative rules with a heterogeneous committee." American fournal of Political Science 33(2): 459-490.

Gutmann, Amy, and Dennis F. Thompson. 2014. The Spirit of Compromise: Why Governing Demands It and Campaigning Undermines It. Princeton, NJ: Princeton University Press.

Hadzic, Dino, and Margit Tavits. 2019. "The gendered effects of violence on political engagement." The fournal of Politics 81(2): 676-680.

Harden, Jeffrey J. 2013. "Multidimensional responsiveness: the determinants of legislators' representational priorities." Legislative Studies Quarterly 38(2): 155-184.

Hertel-Fernandez, Alexander. 2019. State Capture: How Conservative Activists, Big Businesses, and Wealthy Donors Reshaped the American States - and the Nation. Oxford: Oxford University Press.

Hibbing, John R., and Elizabeth Theiss-Morse. 1995. Congress as Public Enemy: Public Attitudes Toward American Political Institutions. New York: Cambridge University Press.

Hobolt, Sara Binzer, and Robert Klemmensen. 2008. "Government responsiveness and political 
competition in comparative perspective." Comparative Political Studies 41(3): 309-337.

Holmberg, Sören. 1999. "Wishful thinking among European parliamentarians." In Hermann Schmitt, and Jacques Thomassen (eds.) Political Representation and Legitimacy in the European Union. Oxford University Press: 235-253.

Homola, Jonathan. 2019. “Are parties equally responsive to women and men?” British fournal of Political Science 49(3): 957-975.

Krehbiel, Keith. 1992. Information and legislative organization. Ann Arbor, MI: University of Michigan Press.

Lax, Jeffrey R., and Justin H. Phillips. 2012. "The democratic deficit in the states." American Journal of Political Science 56(1): 148-166.

Lerner, Jennifer S., Roxana M. Gonzalez, Deborah A. Small, and Baruch Fischhoff. 2003. "Effects of fear and anger on perceived risks of terrorism: A national field experiment.” Psychological Science 14(2): 144-150.

Lodge, Milton, and Charles S. Taber. 2013. The Rationalizing Voter. Cambridge, UK: Cambridge University Press.

Makse, Todd. 2020. "Expertise and the Championing of Policy Innovations in State Legislatures." Policy Studies fournal. Available online at: https : //doi . org/10 . 1111/ps j . 12380

Mattson, Ingvar, and Kaare Strøm. 1995. "Parliamentary committees." In Parliaments and Majority Rule in Western Europe ed. H. Doring: 249-307. New York: St. Martin’s.

Miler, Kristina. 2017. "How Committees Shape Legislative Behavior: An Examination of Interests and Institutions." American Politics Research 45(5): 813-839.

Miller, Warren E., and Donald E. Stokes. 1963. "Constituency influence in Congress." American Political Science Review 57(1): 45-56.

Naurin, Elin, and Patrik Öhberg. 2018. “The Party’s View of Dyadic Responsiveness: A Survey Experiment in Sweden." Scandinavian Political Studies 41.2: 121-143.

O’Grady, Tom. 2019. "Careerists versus coal-miners: welfare reforms and the substantive representation of social groups in the British labour party." Comparative Political Studies 52(4): 544-578.

Öhberg, Patrik, and Elin Naurin. 2016. "Party-constrained policy responsiveness: A survey experiment on politicians' response to citizen-initiated contacts." British fournal of Political Science 46(4): 785-797.

Ottati, Victor, Erika D. Price, Chase Wilson, and Nathanael Sumaktoyo. 2015. "When selfperceptions of expertise increase closed-minded cognition: The earned dogmatism effect." fournal of Experimental Social Psychology 61: 131-138.

Palmiero, Massimiliano, Paola Guariglia, Rosalia Crivello, and Laura Piccardi. 2020. "The relationships between musical expertise and divergent thinking." Acta Psychologica: 102990. 
Pereira, Miguel M. 2020. “Responsive Campaigning: Evidence from European Parties.” The fournal of Politics 82(4): 1183-1195.

Pitkin, Hanna. 1967. The concept of representation. Oakland: University of California Press.

Sheffer, Lior, Peter John Loewen, Stuart Soroka, Stefaan Walgrave, and Tamir Sheafer. 2018. "Nonrepresentative representatives: an experimental study of the decision making of elected politicians." American Political Science Review 112(2): 302-321.

Shepsle, Kenneth A., and Barry R. Weingast. 1994. "Positive theories of congressional institutions." Legislative Studies Quarterly 9(2): 149-179.

Somer-Topcu, Zeynep. 2009. "Timely decisions: The effects of past national elections on party policy change." The fournal of Politics 71(1): 238-248.

Soroka, Stuart N., and Christopher Wlezien. 2010. Degrees of Democracy: Politics, Public Opinion, and Policy. Cambridge University Press, 2010.

Strøm, Kaare. 1998. "Parliamentary committees in European democracies." The fournal of Legislative Studies 4(1): 21-59.

Tetlock, Philip. 2005. Expert Political fudgment: How Good Is It? How Can We Know? Princeton, NJ: Princeton University Press.

Trafimow, David, and Janet A. Sniezek. 1994. "Perceived expertise and its effect on confidence." Organizational Behavior and Human Decision Processes 57(2): 290-302.

Wilkinson, Annie, and James Fairhead. 2017. "Comparison of social resistance to Ebola response in Sierra Leone and Guinea suggests explanations lie in political configurations not culture.” Critical Public Health 27(1): 14-27. 